\title{
Responsiveness and minimal important differences after revision total hip arthroplasty
}

\author{
Hon-Yi Shi' ${ }^{1}$ Je-Ken Chang ${ }^{2}$, Chi-Yin Wong ${ }^{3}$, Jun-Wen Wang ${ }^{4}$, Yuan-Kun Tư ${ }^{5}$, Herng-Chia Chiu' ${ }^{1}$ King-Teh Lee ${ }^{1 *}$
}

\begin{abstract}
Background: The health-related quality of life (HRQoL) is currently weighted more heavily when evaluating health status, particularly regarding medical treatments and interventions. However, it is rarely used by physicians to compare responsiveness. Additionally, responsiveness estimates derived by the Harris Hip Score (HHS) and the Short Form 36 (SF-36) before and after revision total hip arthroplasty (THA) have not been clinically compared. This study compared responsiveness and minimal important differences (MID) between HHS and SF-36.

Methods: All revision THA patients completed the disease-specific HHS and the generic SF-36 before and 6 months after surgery. Scores using these instruments were interpreted by generalized estimating equation (GEE) before and after revision THA. The bootstrap estimation and modified Jacknife test were used to derive 95\% confidence intervals for differences in the responsiveness estimates.

Results: Comparisons of effect size (ES), standardized response means (SRM), relative efficiency (RE) (>1) and MID indicated that the responsiveness of HHS was superior to that of SF-36. The ES and SRM for pain and physical functions in the HHS were significantly larger than those of the SF-36 $(p<0.001)$.

Conclusion: The data in this study indicated that clinicians and health researchers should weight disease-specific measures more heavily than generic measures when evaluating treatment outcomes.
\end{abstract}

\section{Background}

Pain and physical function outcomes of total hip arthroplasty (THA) have been well documented during the past twenty years $[1,2]$. This intervention has proven safe and effective for improving health-related quality of life (HRQoL) [3].

Various HRQoL instruments have been used with increasing frequency during the past decade [3]. Disease-specific measures are traditionally administered in longitudinal studies to detect progressive changes in health and quality of life after interventions and tend to focus on physical function and pain. Conversely, generic measures are designed to assess the effects of any disease or condition and have value for measuring health status. The Harris Hip Score (HHS) is a commonly used physician assessment of physical functioning and pain relief on clinical sites [4]. The Medical Outcomes Study Short Form-36 Health Survey (SF-36) is a self-

\footnotetext{
* Correspondence: hshi@kmu.edu.tw

'Graduate Institute of Healthcare Administration, Kaohsiung Medical

University, 100, Shih-Chun $1^{\text {st }}$ Road, Kaohsiung, Taiwan

Full list of author information is available at the end of the article
}

administered generic HRQoL instrument commonly used to assess overall outcome [5].

Responsiveness is measured by comparing changes in clinical endpoints and changes in instrument outcomes over time in either observational or clinical trials [6,7]. Responsiveness is an important consideration when selecting HRQoL measures for clinical trials or medical interventions. Minimal important difference (MID) is defined as the smallest change in a score for a patient that indicates an actual change between two time points; that is, the MID is the minimum change in a score that likely reflects actual change rather than a variation in measurement $[8,9]$.

The HRQoL is currently weighted more heavily when evaluating health status, particularly regarding medical treatments and interventions. Nevertheless, it is easy to identify the statistical significance of any such changes, but it can be harder to determine whether these changes are clinically or not clinically important. The MID is a statistical value arising from the variance in measure [8]. However, it is rarely used by physicians to compare responsiveness. Additionally, responsiveness estimates 
derived by the SF-36 and the HHS before and after revision THA has not been clinically compared.

In this prospective cohort study, two well-known HRQoL instruments, the SF-36 and the HHS, were used to compare responsiveness and MID in revision THA patients.

\section{Methods}

\section{Patients and data collection}

Two HRQoL instruments were used to survey all patients who underwent revision THA performed by either of two experienced surgeons practicing at two academic hospitals in southern Taiwan between October, 2007 and December, 2008. Eight procedures performed by other low-volume surgeons who had performed less than three procedures annually were excluded from analysis. Patients with cognitive impairment, severe organ or psychiatric diseases $(n=5)$ were excluded. Of the seventy-two eligible subjects who gave written consent and were enrolled in the study at baseline, five were excluded because they did not undergo postoperative assessments. Sixty-seven patients who completed preoperative and 6-month surveys after revision THA were enrolled in the study. Immediately before surgery, the two operating surgeons administered the HHS and a trained research assistant administered the SF-36 Health Survey. The same orthopaedists and research assistant continued to use these instruments to assess HRQoL in the 6-month survey.

\section{Outcome measures}

The two HRQoL survey instruments in this study were the generic Chinese version of the SF-36 and the Harris Hip Score. The SF-36 Health Survey, a widely used measure of generic HRQoL, includes thirty-six items for evaluating physical functioning, role limitations due to physical problems, bodily pain, general health, vitality, social functioning, role limitations due to emotional problems and mental health. Each SF-36 subscale was converted to a scale from 0 to 100 ; the higher score, the better the HRQoL. A translated version of the SF-36 has been validated in Chinese populations [10].

The HHS ranges from 1 to 100 points, and its domains include pain function (1 item), physical function (7 items), deformity (5 items), and range of motion (5 items) [5]. Pain and physical functions are the two basic considerations and are weighted most heavily in the HHS calculation (44 and 46 points, respectively). Physical functions are classified as daily life activities (3 items, 13 points) and gait (4 items, 33 points). Deformity and range of motion are seldom of primary importance and thus each received 5 points. The higher the score, the better the HRQoL implies.

\section{Statistical Analysis}

The unit of analysis was the individual patient. To compare SF-36 and HHS subscales, raw scores were transformed and scaled from 0 to 100, with higher scores correlating with improved HRQoL.

The generalized estimating equation (GEE) approach is similar to that of repeated measure ANOVA but is more powerful because it can accommodate incomplete data for individual subjects at one or more assessment points without compromising the remaining data for the subject. This approach is also advocated for analyzing incomplete data in longitudinal studies with continuous outcomes [11,26] J. Twisk, Applied longitudinal data analysis for epidemiology, Cambridge University Press, Cambridge (2003). The GEE approach was employed to compare longitudinal changes in SF-36 and HHS subscales before and six months after revision THA. Each HRQoL subscale was used as a dependent variable as a function of time and covariates: age, gender, number of comorbidities, average length of stay and re-hospitalization in 30 days. Variables were entered into the GEE analysis as covariates because they were statistically significant in the univariate analysis and have proven to be consistent predictors of HRQoL in many previous studies [3-5].

Responsiveness estimates were evaluated in terms of percentage of change (PC), effect size (ES) [6-8], standardized response mean (SRM) [6-8] and relative efficiency (RE) [12]. The PC was presented as the mean change scores divided by the baseline scores. The ES was calculated by dividing mean change score by the standard deviation of baseline scores. The SRM was calculated as the mean change score divided by the standard deviation of changed scores. Relative efficiency $(\mathrm{RE})$ is defined as the ratio of the square of the $t$-statistic of the comparator instrument (here, each SF-36 subscale score) over the square of the $t$-statistic of the reference instrument (here, HHS total score). An RE score of 1.0 indicates that the SF-36 is as efficient as the HHS in detecting differences in external indicators of health status. If RE exceeds 1.0, the SF-36 is more efficient than the HHS at detecting differences in external indicators of health status. If RE is lower than 1.0, the SF-36 is less efficient than the HHS. It has been suggested that a one-half standard deviation (SD) change of the mean difference in scores may approximate an MID for some patient-reported outcome instruments, and that evidence from previous studies, physiologic arguments, and statistical theory shows a tendency to converge to the one-half-SD criteria as being meaningful to patients [8,13]. An MCID value was determined by multiplying the SD of the mean difference in scores by 0.5 .

Repeated assessment of a single patient can cause complications due to highly correlated observations 
within the same patient. To address these issues, the bias-corrected and accelerated bootstrap method with 2,000 replications and the modified Jacknife test were used to compare responsiveness estimates between two HRQoL instruments $[9,14]$. Bootstrapping is a technique for re-sampling numerous random samples drawn from the original sample with replacement [14]. Within each of these samples, calculating the parameter of interest yields an empirical sampling distribution of the estimator of interest from which, without parametric assumptions, probability statements and confidence intervals can be derived. Differences in ES and SRM between the HHS and the SF-36 were estimated, and the bootstrapping method was used to obtain $95 \%$ confidence intervals for these differences. The modified Jacknife method is a linear regression between the difference in ES or SRM between two comparable scores (e.g., between SF36 bodily pain and HHS pain function) as the dependent variable and the centered ES/SRM of one of the two scales (either scale is appropriate) as the independent variable [9]. A regression intercept (value of the SRM/ ES difference at which the centered ES/SRM equals zero) larger or smaller than zero with significance $\mathrm{p}<$ 0.05 indicates that the two scales significantly differ in responsiveness.

All statistical analyses were performed using Stata Statistical Package, Version 9.0 (Stata Corp, College Station, TX). A p value $<0.05$ was considered statistically significant.

\section{Results}

The study sample included twenty-nine (43\%) female and thirty-eight $(57 \%)$ males with a mean age of 70.2 years (standard deviation, 13.1 years; range, 50-92 years). Preoperatively, each patient exhibited an average of 0.6 co-morbidities, and the average length of stay was 6.4 days (standard deviation, 1.7 days). The subjects who remained in the study and those who were lost to follow-up did not significantly differ in baseline age, gender, number of co-morbidities, 30-day re-hospitalization, SF-36 subscale scores, or HHS subscale scores. Therefore, subjects with incomplete information during the study period were assumed to have no significant confounding effects on the statistical results (data not shown). The sample size in this study was sufficient to detect a ten-point difference over time in all SF-36 and HHS subscales, assuming an $\alpha$ of 0.05 , a power of $80 \%$, an inter-temporal, between-score correlation of 0.70 and standard deviation of $10[4,10]$. This study was approved by the Institutional Review Board of Kaohsiung Medical University Hospital and Kaohsiung Veterans General Hospital in Taiwan.

Longitudinal changes in all SF-36 and HHS subscales revealed statistically significant improvement $(\mathrm{P}<0.05)$ after adjustment for baseline age, gender, education, number of co-morbidities, operation time, average lengths of stay and re-hospitalization in 30 days (Table 1). The SF-36 and the HHS before and 6 months after revision THA revealed improvement rates of from $12.7 \%$ to $52.8 \%$ and from $100.0 \%$ to $180.0 \%$, respectively. Further, the GEE approach produced the highest mean scores for HHS deformity and range of motion subscales 6 months after revision THA. Specifically, as compared to a relatively low score of 29.6 before revision THA, the mean SF-36 score for role limitations due to physical problems was 41.3 after revision THA, an improvement of $39.8 \%$. The mean SF-36 score for role limitations due to emotional problems changed from 59.0 to 90.2 , indicating the role limitations due to emotional problems was the most improved subscale, with an improvement rate of $52.8 \%$. The least improved SF-36 subscale was physical functioning and bodily pain, with an improvement rate of $12.7 \%$ and $12.5 \%$, respectively.

The MID in the HHS pain function, physical function, deformity, and total scores (range from 2.28 to 11.26) are generally higher than those of the SF-36 subscales (range from 12.37 to 22.81), except physical functioning and role limitations due to physical problems, during the study period (Table 1). Therefore, the correlation between the HHS and the SF-36 required use of the bootstrap and the modified Jacknife methods to analyze differences in responsiveness.

Because the HHS subscale deformity and range of motion cannot be compared with any SF-36 subscale, we choose physical function and pain function for responsiveness differences comparison (Table 2). The difference may be considered statistically significant at the 0.05 significance level if the confidence interval excludes zero. The HHS revealed significant increases in the ES and SRM of physical function and pain function between the preoperative and 6-month surveys [ES of difference in physical function 6.27 (95\% CI: 5.84 to 6.69) and SRM of difference in physical function 10.42 (95\% CI: 9.92 to 10.92); ES of difference in pain function 5.50 (95\% CI: 5.05 to 5.95) and SRM of difference in pain function 8.61 (95\% CI: 8.21 to 9.00)]. Overall, the HHS was statistically more responsive than the SF-36 was in terms of physical function and pain function measurements $(\mathrm{p}<0.001)$.

\section{Discussion}

Based on the assessments of the HHS and the SF-36, this comparative study yielded systematic and comprehensive data regarding responsiveness and MID in patients undergoing revision THA.

Analysis of longitudinal changes indicated the role limitations due to physical and emotional problems of 
Table 1 Estimated responsiveness and minimal important differences (MID) for the SF-36 and the Harris Hip Score $(\text { HHS })^{\S}$

\begin{tabular}{|c|c|c|c|c|c|c|c|c|c|}
\hline \multirow[b]{2}{*}{ Subscale } & \multirow[b]{2}{*}{ Mean (S.D.) } & \multirow[b]{2}{*}{ Mean (S.D.) } & \multirow[b]{2}{*}{ Mean (S.D.) } & \multirow[b]{2}{*}{$P$ value } & \multicolumn{4}{|c|}{ Indicators of responsiveness } & \multirow[t]{2}{*}{ MID } \\
\hline & & & & & PC (\%) & ES & SRM & RE & \\
\hline \multicolumn{10}{|l|}{ SF-36 } \\
\hline PF & $64.1(6.7)$ & $72.2(6.4)$ & $8.1(6.5)$ & $<0.001$ & 12.67 & 1.22 & 1.25 & 0.07 & 3.25 \\
\hline $\mathrm{RP}$ & $29.6(14.3)$ & $41.3(7.2)$ & 11.8(9.6) & $<0.001$ & 39.77 & 0.82 & 1.23 & 0.10 & 4.78 \\
\hline RE & $59.0(36.2)$ & $90.2(43.7)$ & $31.2(40.0)$ & $<0.001$ & 52.80 & 0.86 & 0.78 & 0.33 & 19.98 \\
\hline SF & $69.8(45.9)$ & $88.2(47.2)$ & $18.4(31.7)$ & $<0.001$ & 26.30 & 0.40 & 0.58 & 0.21 & 15.83 \\
\hline $\mathrm{BP}$ & $73.7(22.5)$ & $82.9(24.5)$ & $9.2(29.8)$ & $<0.001$ & 12.54 & 0.41 & 0.31 & 0.09 & 14.91 \\
\hline VT & $53.4(34.0)$ & $76.2(36.0)$ & $22.8(45.6)$ & $<0.001$ & 42.71 & 0.67 & 0.50 & 0.21 & 22.81 \\
\hline $\mathrm{MH}$ & $69.4(21.4)$ & $82.2(22.3)$ & $12.9(24.7)$ & $<0.001$ & 18.54 & 0.60 & 0.52 & 0.11 & 12.37 \\
\hline $\mathrm{GH}$ & $64.1(42.3)$ & $78.5(48.2)$ & $14.4(28.2)$ & $<0.001$ & 22.46 & 0.34 & 0.51 & 0.12 & 14.12 \\
\hline \multicolumn{10}{|l|}{$\mathrm{HHS}$} \\
\hline Pain & $34.1(10.4)$ & $95.4(15.7)$ & $61.4(6.9)$ & $<0.001$ & 179.99 & 5.91 & 8.92 & 0.57 & 3.44 \\
\hline Function & $35.9(7.1)$ & 89.1(9.4) & $53.3(4.6)$ & $<0.001$ & 148.48 & 7.49 & 11.67 & 0.49 & 2.28 \\
\hline Deformity & $50.0(11.7)$ & $100.0(20.0)$ & $50.0(22.5)$ & $<0.001$ & 100.00 & 4.28 & 2.22 & 0.67 & 11.26 \\
\hline Motion & $50.0(10.1)$ & $100.0(14.7)$ & $50.0(35.7)$ & $<0.001$ & 100.00 & 4.95 & 1.40 & 0.72 & 17.86 \\
\hline Total scores & $36.5(6.6)$ & $93.0(17.8)$ & $56.5(4.9)$ & $<0.001$ & 154.79 & 8.57 & 11.58 & 1.00 & 2.44 \\
\hline
\end{tabular}

${ }^{\S} \mathrm{PC}=$ percentage of change; $\mathrm{ES}=$ effect size; $\mathrm{SRM}=$ standard responsiveness means; $\mathrm{RE}=$ relative efficiency; $\mathrm{CL}=95 \%$ confidence interval at lower limit; $\mathrm{CU}=$ $95 \%$ confidence interval at upper limit; $\mathrm{PF}=$ physical functioning; $\mathrm{RP}=$ role limitations due to physical problems; $\mathrm{RE}=$ role limitations due to emotional problems; SF = social functioning; $\mathrm{BP}=$ bodily pain; $\mathrm{VT}=$ vitality; $\mathrm{MH}=$ mental health; $\mathrm{GH}$ = general health; Pain = pain function; Function = physical function; Deformity $=$ deformity; Motion $=$ range of motion.

the SF-36 exhibited the highest improvement rate. Before surgery, the mean scores for physical and emotional roles were relatively lower than those for any other scale, probably because these roles were limited by the physical and emotional function of patients. The patients could resume their role limitations immediately after revision THA. Consequently, improved role limitations might improve vitality, social functions, general health, mental health and as well as overall quality of life. However, the areas of pain relief and physical function revealed relatively poorer improvement than other functions. This might implicate there was a trend for patients who had had more severe functional problems before the surgery to have poorer pain and physical functions after revision THA [15]. Nevertheless, the items for the role subscales have 5 possible answer levels in version 2 of the SF-36 instead of 2 (present/ absent) in version 1 . The role subscales are measured more fine graded and more differentiated. The range of possible scores has increased and differences (baseline to follow-up) can be measured more precisely by version 2 [16].

This study is the first to compare the HHS and the SF-36 for responsiveness and MID in revision THA patients treated at two medical centers. The data derived by this study can help clinicians and health researchers decide which measure is most effective for evaluating HRQoL before and after revision THA. The responsiveness estimates for the HHS generally exceeded 0.5 , which can be interpreted as medium change $[17,18]$. Partial subscales of the SF-36 also presented good results in responsiveness estimates and MID, which revealed improvement after surgery. This study also revealed the close algebraic relationship and conceptual differences between ES and SRM estimates, which is consistent with an earlier report by Zou [19].

Schmitt and Fabio [20] contrasted the use of responsiveness indicators at the group level versus the individual patient level. While several other studies in orthopedic surgery and medicine have used MID to

Table 2 Comparative responsiveness estimates of effect size (ES) and standardized response mean (SRM) of the SF-36 and the Harris Hip Score (HHS)

\begin{tabular}{|c|c|c|c|c|}
\hline & \multicolumn{4}{|c|}{ HHS - SF-36 } \\
\hline & ES (Estimate $[95 \% \mathrm{Cl}])^{\S}$ & SRM (Estimate $[95 \% \mathrm{Cl}])^{\S}$ & $p(E S)^{*}$ & $\mathrm{p}(\mathrm{SRM})^{*}$ \\
\hline Physical function & $6.27(5.84,6.69)$ & $10.42(9.92,10.92)$ & $<0.001$ & $<0.001$ \\
\hline Pain function & $5.50(5.05,5.95)$ & $8.61(8.21,9.00)$ & $<0.001$ & $<0.001$ \\
\hline
\end{tabular}

${ }^{\S}$ Differences are presented in effect size and standardized response means (95\% confidence interval obtained by bootstrapping).

* $\mathrm{p}$ : Type I error of the modified Jacknife test comparing two ES or two SRM. 
compare HRQoL instruments [4,7], no investigators have applied MID calculations to the HHS.

Importantly, although the improvements were in different subscales of the HHS and the SF-36, the estimated responsiveness of the HHS generally was greater than that of the SF-36. However, such the responsiveness estimates in previous studies $[3,15]$ were made using a small sample size or lacked comparative statistical data before and after interventions. Thus, the bootstrap method employed in this study generated a $95 \%$ confidence interval. Although the two measures significantly differed in responsiveness, each exhibited superior responsiveness in different subscales. The HHS exhibited superior responsiveness in physical function and pain function subscales.

An acknowledged limitation of this study is the small sample size, which restricts the extent to which the findings can be generalized to larger populations. Future studies are needed to examine outcomes, patient attributes, hospital attributes, care quality, preoperative functional status and related factors in a larger population. Further, the patient outcome may be highly dependent on variables such as operator proficiency, advancing technology and available facilities [21]. However, all procedures evaluated in this study were performed by surgeons with the most experience in revision THA procedures in each of two different institutions, and the potential confounding factors in both responsiveness and MID were controlled simultaneously. Given this design, the surgical outcomes in this study were more representative than those of a single-surgeon study.

To confirm the data regarding the responsiveness and MID of the HHS and the SF-36 scores, Table 3 presents an international data comparison. The findings of this

Table 3 Comparative responsiveness and minimal important differences (MID) of health-related quality of life (HRQoL) instruments reported in previous studies

\begin{tabular}{|c|c|c|c|c|c|}
\hline Authors & Country & No. of subjects & $\begin{array}{l}\text { Measurement } \\
\text { time intervals }\end{array}$ & Instrument* & Findings \\
\hline $\begin{array}{l}\text { Shi HY, et al. } \\
\text { (present study) }\end{array}$ & Taiwan & 67 revision THA & $\begin{array}{l}\text { Preoperative } \\
\text { and 6-month } \\
\text { surveys }\end{array}$ & HHS, SF-36 & $\begin{array}{l}\text { HHS revealed greater overall responsiveness than } \\
\text { the SF-36 between pre-op and 6-month surveys. }\end{array}$ \\
\hline $\begin{array}{l}\text { Soohoo NF, et } \\
\text { al. (2007)[7] }\end{array}$ & U.S. & 89 primary THA & $\begin{array}{l}\text { Preoperative } \\
\text { and } 5 \text { to } 17- \\
\text { month surveys }\end{array}$ & WOMAC, SF-36 & $\begin{array}{l}\text { The standardized response means (SRM) for the } \\
\text { WOMAC ranged from }-0.93 \text { to }-1.49 \text {, and the effect } \\
\text { size (ES) ranged from }-1.02 \text { to }-1.53 \text {. The SRM for } \\
\text { the SF- } 36 \text { ranged from } 0.22 \text { to } 1.64 \text {, and the ES } \\
\text { ranged from } 0.20 \text { to } 1.97 \text {. }\end{array}$ \\
\hline $\begin{array}{l}\text { Quintana JM, } \\
\text { et al. (2005) } \\
{[22]}\end{array}$ & Spain & 310 primary $\mathrm{THA}$ & $\begin{array}{l}\text { Preoperative, 6- } \\
\text { and 24-month } \\
\text { surveys }\end{array}$ & WOMAC, SF-36 & $\begin{array}{l}\text { WOMAC exhibited treatment responsiveness } \\
\text { superior to the SF-36. The percentage of minimal } \\
\text { detectable change (MDC) was higher than } 80 \% \text { for } \\
\text { all WOMAC domains, except stiffness ( } 60 \% \text { ), while } \\
\text { it was higher than } 40 \% \text { in the physical domains of } \\
\text { the SF-36 (physical function, physical role, or } \\
\text { bodily pain). }\end{array}$ \\
\hline $\begin{array}{l}\text { Angst F, } \\
\text { et al. (2001) } \\
{[23]}\end{array}$ & Switzerland & 433 hip or knee OA & $\begin{array}{l}\text { Preoperative } \\
\text { and 3-month } \\
\text { surveys }\end{array}$ & WOMAC, SF-36 & $\begin{array}{l}\text { SRM }=0.723 \text { for WOMAC and SRM }=0.528 \text { for SF- } \\
36 \text { at the end of rehabilitation; SRM }=0.377 \text { for } \\
\text { WOMAC and SRM }=0.468 \text { for SF- } 36 \text { at the three } \\
\text { month follow up. In the measurement of function, } \\
\text { the WOMAC was significantly more responsive } \\
\text { than the SF-36 (SRMs, end of rehabilitation: } 0.628 \\
\text { vs. } 0.249 \text {; three month follow up: } 0.235 \text { vs. }-0.001 \text { ). }\end{array}$ \\
\hline $\begin{array}{l}\text { Hoeksma HL, } \\
\text { et al. (2003) } \\
{[24]}\end{array}$ & Netherlands & 75 hip OA & $\begin{array}{l}\text { Preoperative } \\
\text { and 5-week } \\
\text { surveys }\end{array}$ & HHS, SF-36 & $\begin{array}{l}\text { The responsiveness ratio for the HHS was high } \\
\text { (1.70) compared with walking speed }(0.45) \text {, pain } \\
\text { during walking }(0.66) \text {, and the subscales of the SF- } \\
36 \text {-"bodily pain" }(0.42) \text { and "physical functioning" } \\
(0.36) \text {. }\end{array}$ \\
\hline $\begin{array}{l}\text { Weigl M, et al. } \\
(2006)[25]\end{array}$ & Germany & $\begin{array}{l}439 \text { low (upper) back pain } \\
\text { and conditions of the lower } \\
\text { (upper) extremities patients }\end{array}$ & $\begin{array}{l}\text { Preoperative } \\
\text { and } 2 \sim 4 \text {-week } \\
\text { surveys }\end{array}$ & $\begin{array}{l}\text { SCQ SF-36 NASS } \\
\text { DASH }\end{array}$ & $\begin{array}{l}\text { The condition-specific instruments demonstrated a } \\
\text { good responsiveness with an ES ranging between } \\
0.28 \text { and } 0.55 \text { and with a SRM between } 0.32 \text { and } \\
0.94 \text {. The responsiveness of the SF- } 36 \text { Physical } \\
\text { Function scale showed a lower responsiveness } \\
\text { than the condition-specific scales. }\end{array}$ \\
\hline $\begin{array}{l}\text { Lübbeke A, et } \\
\text { al. (2007) [26] }\end{array}$ & Switzerland & $\begin{array}{l}435 \text { primary } \mathrm{THA}, 116 \\
\text { revision THA }\end{array}$ & $\begin{array}{l}\text { Preoperative } \\
\text { and 5-year } \\
\text { surveys }\end{array}$ & $\begin{array}{l}\text { HHS, WOMAC, } \\
\text { SF-12 }\end{array}$ & $\begin{array}{l}\text { HHS and WOMAC were relatively more responsive } \\
\text { for physical and pain functions than the SF-12. }\end{array}$ \\
\hline
\end{tabular}

*HHS = Harris Hip Score, SF-36 = Medical Outcomes Study Short Form-36 Health Survey, WOMAC = Western Ontario and McMaster Universities Osteoarthritis Index, SCQ = Self-administered Comorbidity Questionnaire, NASS = North American Spine Society Questionnaire, DASH = Disabilities of Arm, Shoulder, and Hand Questionnaire 
study were compared with those similar studies of United States and European populations [7,22-26]. These studies were selected because they were similar to the current study in terms of sample size, mean age of the population, measurement time points (including preoperation and at least 6 months postoperative), and, most importantly, the use of both disease-specific and generic measures. The current finding of greater responsiveness of the disease-specific measure in comparison with the generic measure was consistent with all comparable studies examined. Specifically, the increased responsiveness of the disease-specific measure suggests that physical and related functions improve more rapidly and more completely than overall quality of life in patients who undergo revision THA.

\section{Conclusion}

The comparative results of this prospective observational study provide comprehensive and systematic information regarding the expected responsiveness and MID in patients undergoing revision THA. The HHS exhibited responsiveness superior to that of the SF-36 between the preoperative and 6-month surveys. Therefore, clinicians and health researchers may consider weighting the HHS more heavily than the SF-36 to determine treatment effectiveness. Further study may also examine the extent to which the HRQoL instrument is applicable to other forms of orthopaedic surgery.

\section{Acknowledgements \\ This work was supported by a grant from the National Science Council, Taiwan (NSC96-2314-B-037-050-MY3).}

\section{Author details \\ ${ }_{1}^{1}$ Graduate Institute of Healthcare Administration, Kaohsiung Medical University, 100, Shih-Chun $1^{\text {st }}$ Road, Kaohsiung, Taiwan. ${ }^{2}$ Department of Orthopaedics, Kaohsiung Medical University Hospital 100, Tzyou $1^{\text {st }}$ Road, Kaohsiung, Taiwan. ${ }^{3}$ Department of Orthopaedics, Kaohsiung Veterans General Hospital 386, Ta-Chung $1^{\text {st }}$ Road, Kaohsiung, Taiwan. ${ }^{4}$ Department of Orthopaedics, Chang-Gung Memorial Hospital, Kaohsiung Branch 123, Ta-Pei Road, Niao-Sung Hsiang, Kaohsiung, Taiwan. ${ }^{5}$ Department of Orthopaedics, E-Da Hospital 1, Yi-Da Road, Jiau-Shu Shiang, Kaohsiung, Taiwan.}

\section{Authors' contributions}

$\mathrm{HY}$ involved in conception and design, obtaining grants, development of interview guide, acquisition, performed and transcribed the interviews, preparation of data, analyses and interpretation of data, drafting the article. $\mathrm{JK}, \mathrm{CY}, \mathrm{JW}, \mathrm{YK}$, and $\mathrm{HC}$ involved in conception and design, analyses and interpretation of data, substantial contribution in revising the article for important intellectual content. KT involved in conception and design, development of interview guide, analyses and interpretation of data, substantial contribution in revising the article for important intellectual content. All authors have read and approved the final manuscript.

\section{Competing interests}

The authors declare that they have no competing interests.
References

1. Minns Lowe CJ, Barker KL, Dewey ME, Sackley CM: Effectiveness of physiotherapy exercise following hip arthroplasty for osteoarthritis: a systematic review of clinical trials. BMC Musculoskelet Disord 2009, 10:98.

2. Dieppe P, Judge A, Williams S, Ikwueke I, Guenther KP, Floeren M, Huber J, Ingvarsson T, Learmonth I, Lohmander LS, Nilsdotter A, Puhl W, Rowley D, Thieler R, Dreinhoefer K, EUROHIP Study Group: Variations in the preoperative status of patients coming to primary hip replacement for osteoarthritis in European orthopaedic centres. BMC Musculoskelet Disord 2009, 10:19.

3. Nilsdotter AK, Isaksson F: Patient relevant outcome 7 years after total hip replacement for OA - a prospective study. BMC Musculoskelet Disord 2010, 11:47.

4. Hoeksma HL, Van Den Ende CH, Ronday HK, Heering A, Breedveld FC: Comparison of the responsiveness of the Harris Hip Score with generic measures for hip function in osteoarthritis of the hip. Ann Rheum Dis 2003, 62:935-938.

5. Kosinski M, Keller SD, Hatoum HT, Kong SX, Ware JE: The SF-36 Health Survey as a generic outcome measure in clinical trials of patients with osteoarthritis and rheumatoid arthritis: tests of data quality, scaling assumptions and score reliability. Med Care 1999, 37:10-22.

6. Terwee CB, Dekker FW, Wiersinga WM, Prummel MF, Bossuyt PM: On assessing responsiveness of health-related quality of life instruments: guidelines for instrument evaluation. Qual Life Res 2003, 12:349-362.

7. Escobar A, Quintana JM, Bilbao A, Aróstegui I, Lafuente I, Vidaurreta I: Responsiveness and clinically important differences for the WOMAC and SF-36 after total knee replacement. Osteoarthritis Cartilage 2007 15:273-280.

8. Revicki D, Hays RD, Cella D, Sloan J: Recommended methods for determining responsiveness and minimally important differences for patient-reported outcomes. J Clin Epidemiol 2008, 61:102-109.

9. Angst F, Verra ML, Lehmann S, Aeschlimann A: Responsiveness of five condition-specific and generic outcome assessment instruments for chronic pain. BMC Med Res Methodol 2008, 8:26

10. Fuh JL, Wang SJ, Lu SR, Juang KD, Lee SJ: Psychometric evaluation of a Chinese (Taiwanese) version of the SF-36 health survey amongst middle-aged women from a rural community. Qual Life Res 2000, 9:675-683

11. Hardin JW, Hilbe JM: Generalized Estimating Equations. Boca Raton, FL: Chapman \& Hall/CRC; 22003.

12. Liang MH, Larson MG, Cullen KE, Schwartz JA: Comparative measurement efficiency and sensitivity of five health status instruments for arthritis research. Arthritis Rheum 1985, 28:542-547.

13. Judge A, Cooper C, Williams S, Dreinhoefer K, Dieppe P: Patient-reported outcomes one year after primary hip replacement in a European Collaborative Cohort. Arthritis Care Res 2010, 62:480-488.

14. Efron B, Gong G: A leisurely look at the bootstrap, the jackknife, and cross-validation. Am Statistician 1983, 37:36-48.

15. Davis AM, Agnidis Z, Badley E, Kiss A, Waddell JP, Gross AE: Predictors of functional outcome two years following revision hip arthroplasty. $J$ Bone Joint Surg Am 2006, 88:685-691.

16. Taft C, Karlsson J, Sullivan M: Performance of the Swedish SF-36 version 2.0. Qual Life Res 2004, 13:251-256.

17. Cohen J: Statistical power analysis for the behavioural sciences. New York: Academic Press; 1997

18. Kazis $L E$, Anderson JJ, Meenan RF: Effect sizes for interpreting changes in health status. Med Care 1989, 27:S178-S189.

19. Zou GY: Quantifying responsiveness of quality of life measures without an external criterion. Qual Life Res 2005, 14:1545-1552.

20. Schmitt JS, Di Fabio RP: Reliable change and minimum important difference (MID) proportions facilitated group responsiveness comparisons using individual threshold criteria. J Clin Epidemiol 2004, 57:1008-1018.

21. Solomon $D H$, Losina $E$, Baron JA, Fossel AH, Guadagnoli E, Lingard $E A$, Miner A, Phillips CB, Katz JN: Contribution of hospital characteristics to the volume-outcome relationship: dislocation and infection following total hip replacement surgery. Arthritis Rheum 2002, 46:2436-2444.

22. Quintana JM, Escobar A, Bilbao A, Arostegui I, Lafuente I, Vidaurreta I: Responsiveness and clinically important differences for the WOMAC and SF-36 after hip joint replacement. Osteoarthritis Cartilage 2005, 13:1076-2083. 
23. Angst F, Aeschlimann A, Steiner W, Stucki G: Responsiveness of the WOMAC osteoarthritis index as compared with the SF-36 in patients with osteoarthritis of the legs undergoing a comprehensive rehabilitation intervention. Ann Rheum Dis 2001, 60:834-840.

24. Hoeksma HL, Van Den Ende CH, Ronday HK, Heering A, Breedveld FC: Comparison of the responsiveness of the Harris Hip Score with generic measures for hip function in osteoarthritis of the hip. Ann Rheum Dis 2003, 62:935-938.

25. Weigl M, Ewert T, Kleinschmidt J, Stucki G: Measuring the outcome of health resort programs. J Rheumatol 2006, 33:764-770.

26. Lübbeke A, Katz JN, Perneger TV, Hoffmeyer P: Primary and revision hip arthroplasty: 5-year outcomes and influence of age and comorbidity. J Rheumatol 2007, 4:394-400

\title{
Pre-publication history
}

The pre-publication history for this paper can be accessed here: http://www.biomedcentral.com/1471-2474/11/261/prepub

\author{
doi:10.1186/1471-2474-11-261 \\ Cite this article as: Shi et al:: Responsiveness and minimal important \\ differences after revision total hip arthroplasty. BMC Musculoskeletal
}

Disorders 2010 11:261.

\section{Submit your next manuscript to BioMed Central and take full advantage of:}

- Convenient online submission

- Thorough peer review

- No space constraints or color figure charges

- Immediate publication on acceptance

- Inclusion in PubMed, CAS, Scopus and Google Scholar

- Research which is freely available for redistribution

Submit your manuscript at www.biomedcentral.com/submit 